\title{
Evaluation of susceptibility of cassava germplasm to cassava mosaic disease
}

\author{
H. M. S. Prasangika ${ }^{1}$, N. Salim ${ }^{1 *}$ and M. M. Razak ${ }^{2}$ \\ 'Department of Botany, University of Sri Jayewardenepura. \\ 2 Medical Research Institute, Colombo 08.
}

\begin{abstract}
Cassava mosaic disease (CMD) caused by geminiviruses is one of the important diseases of cassava Manihot esculenta Crantz causing severe yield loss. Use of resistant varieties is the most feasible measure to manage virus diseases. Eleven germplasms of cassava including Kirikavadi, MU51 and CARI 555 that are recommended and released for cultivation by the Department of Agriculture (DOA) were evaluated for their susceptibility to cassava mosaic disease. Pot experiments were carried out in a planthouse at $30 \pm 3{ }^{\circ} \mathrm{C}$. Twenty replicates from each germplasm were inoculated by wedge grafting method and were examined for symptoms of CMD. The germplasms $\mathrm{WA} / \mathrm{KK} / 10$ and $555 / \mathrm{KK} / 2$ were highly resistant to CMD infection as assessed by percentage infection and by Triple Antibody Sandwich Enzyme-Linked Immunosorbent Assay (TAS ELISA) tests. All other types (HORDI 28, HORDI 6,CARI 555, MU51, Kirikawadi, BW1, BW2,Wariyapola, and Wagolla) were susceptible to varying degrees. Among the germplasms tested HORDI 6 was highly susceptible to CMD.
\end{abstract}

Keywords: Cassava germplasm, cassava mosaic disease, cassava mosaic geminiviruses, Manihot esculenta Crantz.

\section{INTRODUCTION}

Cassava (Manihot esculenta Crantz) is an important tuber crop and is one of the major sources of carbohydrate that fulfils the dietary requirements of Sri Lankan families with low income. Cassava is cultivated on a small scale and in home gardens in the wet and intermediate zones of Sri Lanka mainly for local consumption. The production however, has now increased to supply the export market ${ }^{1}$.

Cassava mosaic disease (CMD) is the most important viral disease and is caused by several geminiviruses. It occurs in many countries where cassava is grown, and is a limiting factor of cassava production in Africa and India, causing 20-90\% yield-loss ${ }^{2}$. Primary spread of the disease is by stem cuttings obtained from infected plants and the secondary spread is brought about by whitefly vector called Bemisia tabaci (Gennedius) ${ }^{3}$.

CMD in Sri Lanka is reported to be caused by two geminiviruses namely, Sri Lankan cassava mosaic Geminivirus and an isolate of Indian Cassava Mosaic Geminivirus $^{4,5}$. In Sri Lanka the disease was first noticed in early 1980s and was found to occurr in widely separated locations in the wet zone ${ }^{4}$. It spread rapidly within the next two decades and now it is commonly seen in the districts of Colombo, Gampaha and Kurunegala. However, the disease is still not prevalent in the dry zone (authors' unpublished results).

There is no published information on the susceptibility of local cassava varities to CMD. A considerable range of cassava germplasms in Sri Lanka with different morphological, physiological and biochemical characters have been identified ${ }^{6}$. From about eighty germplasms that have been identified, only three, namely kirikavadi, MU51 and CARI 555 have been recommended and released for cultivation by the Department of Agriculture (DOA) as observed by the Regional Agriculture Research and Development Centre (RARDC), Makandura (personal communication). In this study, eleven germplasms including the above three types were screened for their susceptibility to CMD.

\section{METHODS AND MATERIALS}

Stakes of respective germplasms were obtained from RARDC of Makandura. Stem cuttings, 5 inches in length 
were sprouted in plastic pots ( $30 \mathrm{~cm}$ diameter) containing top soil, sand and compost in the ratio of $2: 1: 1$, and maintained in a planthouse at $30 \pm 3{ }^{\circ} \mathrm{C}$. Application of fertilizers was done as recommended by RARDC/ Makandura. The original source of virus was obtained from cassava plants of an unknown variety growing in a home garden at Narahenpita, that showed the characteristic symptoms of CMD. Foliar symptoms included bright yellow mosaic, severe leaf curling and malformations of leaflets. Host range, serology, and electron microscope studies confirmed the association of a geminivirus in these plants ${ }^{5}$. Stakes obtained from infected mother plants were propagated in the botanical garden at the premises of the University of Sri Jayawardanapura, Nugegoda, under insect-proof nettings. All the progeny plants showed severe symptoms of CMD (Figure 1). Triple Antibody Sandwich Enzyme Linked Immunosorbent Assay (TAS ELISA) and particle morphology (Figure 2) observed using the electron microscope (at the Medical Research Institute, Colombo 8) were used to detect and confirm the identity of the virus in the infected plants.

Before inoculation, all test plants were checked for any latent infection after three weeks of planting, using the TAS ELISA test. After confirming the virus free status, the test plants were inoculated with CMD by the wedge grafting method. Infected scions expressing severe symptoms from source plants were used for grafting. In the first experiment 20 replicates of each germplasm were inoculated. In the second experiment $(6 \mathrm{wks}$ after the first experiment) only 10 replicates of each germplasm were used due to the difficulty in obtaining large numbers of infected scions at a time and, also due to the limited space available in the planthouse. In both experiments newly formed lateral shoots were examined for symptom expression. Those plants, which did not show any symptoms after four weeks of first inoculation, were re-inoculated, and any plant that did not show symptoms six weeks after second inoculation, was tested

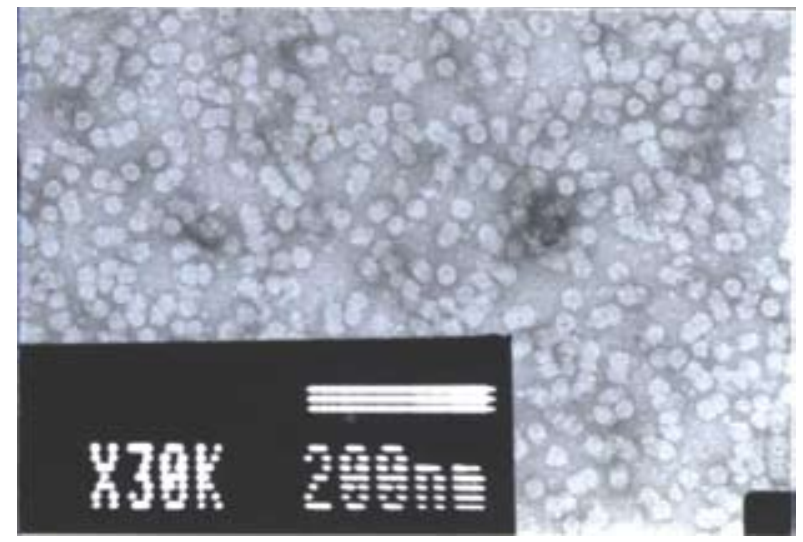

Figure 1: Mosaic and leaf curling symptoms of cassava mosaic disease for latency by TAS-ELISA test. The percentage infection and the degree of susceptibility of each germplasm were calculated as follows.

Percentage infection $=($ Number of plants infected $/$

Number of plant inoculated)x 100

Degree of susceptibility was assessed using an arbitrary scoring system as follows.

$\%$ infection: $0=$ highly resistant, $1-10=$ resistant, 11-20 = less susceptible, $21-50=$ moderately susceptible and $>50=$ highly susceptible

\section{RESULTS}

The results revealed that two of the germplasms tested, namely WA/KK/10 and 555/KK/2 were highly resistant to infection whereas all other types (HORDI 28, HORDI 6, CARI 555, MU51, Kirikawadi, BW1, BW2, Wariyapola, and Wagolla) were susceptible to varying degrees (Table 1). Among them, HORDI 6 was highly susceptible and all the inoculated plants became infected (100\% infection). Other germplasms were either less or moderately susceptible to the disease. Interestingly, it was noted that the 3 varieties released by the DOA for cultivation were among the moderately susceptible types. Further, BW1 which was recently reported as a high-yielding variety and suggested for release ${ }^{1}$, was also found to be susceptible to CMD.

\section{DISCUSSION}

The rapid spread of CMD is due to the routine use of infected stem cuttings, as planting material. Therefore, the development of virus free materials with appropriate resistance would offer a practical means of control over the other methods. In this case, assessment of varietal susceptibility in relation to local infection pressure

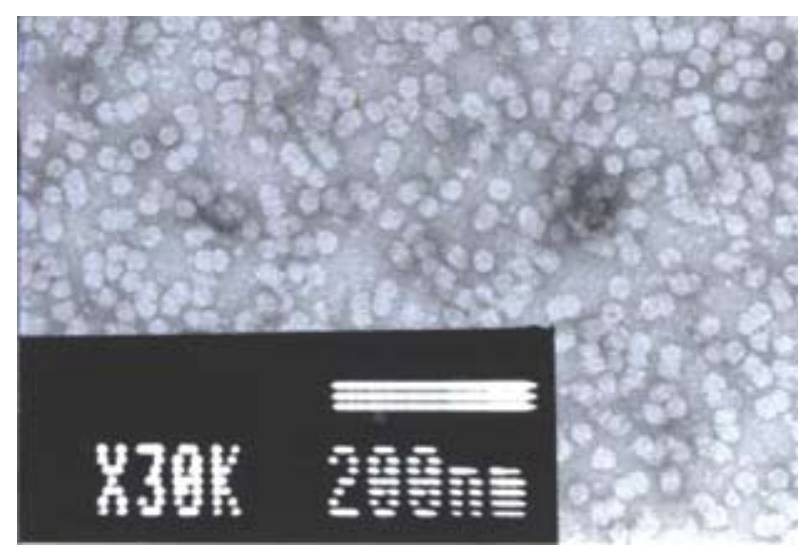

Figure 2: geminate particles in partially purified virus preparation from infected leaves 
Table 1: Reaction of cassava germplasms to cassava mosaic disease.

\begin{tabular}{|c|c|c|c|}
\hline \multirow{2}{*}{ Germplasm } & \multicolumn{2}{|c|}{$\%$ infection } & \multirow{2}{*}{ Degree of susceptibility } \\
\hline & experiment 1 & experiment 2 & \\
\hline $555 / \mathrm{KK} / 2$ & 0 & 0 & highly resistant \\
\hline $\mathrm{WA} / \mathrm{KK} / 1$ & 0 & 0 & highly resistant \\
\hline BW2 & 5 & 10 & resistant \\
\hline Wagolla & 5 & 10 & resistant \\
\hline Wariyapola & $* 15.79$ & 20 & less resistant \\
\hline BW1 & 15 & 20 & less resistant \\
\hline Kirikawadi & 25 & 30 & moderately susceptible \\
\hline Mu 51 & 30 & 40 & moderately susceptible \\
\hline CARI 555 & 45 & 50 & moderately susceptible \\
\hline HORDI 28 & 35 & 40 & moderately susceptible \\
\hline HORDI 6 & $* * 100$ & $* * * 100$ & highly susceptible \\
\hline
\end{tabular}

under field conditions is very important. The present investigation carried out under greenhouse conditions showed that the degree of susceptibility of cassava to $\mathrm{CMD}$ varies with the germplasm. This is probably due to differences in their genetic make up. There were no reports on susceptibility of the three recommended varieties, MU 51, CARI 555 and kirikawadi to CMD at the time they were recommended for cultivation probably because they were resistant to the virus at that time. However, the moderate susceptibility shown at present may probably be due the extensive and widespread cultivation of theses varieties. On the other hand, development of more virulent strains of the virus also cannot be ruled out as it is a common phenomenon among geminiviruses ${ }^{7}$. Similar investigations on varietal assessment in Africa have led to the improvement of new varieties and breeding lines of cassava resistant to $\mathrm{CMD}^{8}$. Intercrossing between resistant varieties has given very high levels of resistance to CMD by concentrating the recessive genes for resistance 9 . The two highly resistant types, namely, 55/KK/2 and $\mathrm{WA} / \mathrm{KK} / 10$ found in this investigation can be used to improve cassava germplasm by breeding.

\section{CONCLUSION}

The degree of susceptibility of cassava to CMD varies with the cassava germplasm. Among the eleven types tested, HORDI 6 was highly susceptible and 555/KK/2 and WA/KK/10 were highly resistant. The three cassava varieties, which are recommended and released by the
DOA for cultivation, are also moderately susceptible to the disease.

\section{Acknowledgement}

The RARDC/Makandura is gratefully acknowledged for providing planting material of cassava. This work was partly funded by the University Grant ASP/ 04 /PR/ 96/ 04.

\section{References}

1. Harischandra S.N., de Silva K.K.N., Kahandawela J.B.D.S $\&$ Wickramasingha C.D. (2005). Performance of three high yielding cassava (Manihot esculenta Crantz) varieties. Annals of the Sri Lanka Department of Agriculture 7: 353-356.

2. Lozano J.C. \& Booth R.H. (1976). Virus and mycoplasm-like diseases. In: Diseases of cassava, second edition, pp. 11-14. Centro Intronacional de Agricultura Tropical, Cali, Colombia.

3 Storey H.H. \& Nicholas R.F.W. (1938). Studies on the mosaic disease of cassava. Annals of Applied Biology 25:760-806.

4. Keith S., Salim N., Mali V.R, Malathi V.G., Markham P.G. \& Stanley J. (2002). Characterization of Sri Lankan cassava mosaic virus: evidence for acquisition of a DNA B component by a monopartite begomovirus. Virology 293 (1): 63-74.

5. Salim N. \& Bandumala S.H. (2001). Characterization of a geminivirus that infects cassava in Sri Lanka. Vidyodaya Journal of Science 10: 151-165. 
6. Jayawardene S.D.G. (1986). Cassava, in the Agricultural economy of Sri Lanka. In: Cassava in Asia, It's potential and research development needs. Proceeding of the Regional workshop held in Bangkok, Thailand, 5-8 June, 1984. Cali, Colombia, pp.115-129.

7. Verma A., \& Malathi V.G. (2003). Emerging geminivirus problems: A serious threat to crop production. Annals of Applied Biology 142: 145-164.
8. Otim-Nape G.W., Bua A., Thresh J.M., Baguma Y., Ogwal S., Ssemakula G.N., Acola G., Byabakama B. \& Martin A. (1997). Cassava Mosaic Disease in Uganda: The Current Pandemic and Approaches to Control. National Research Institute, Chatham, UK.

9. Jennings D.L. (1984). Breeding for resistant to African cassava mosaic virus in East Africa. Tropical Science $\mathbf{3 4}$ (1): 110-122. 